\title{
Housing Insecurity Among Latinxs
}

\author{
Melissa Chinchilla ${ }^{1}$ (1) $\cdot$ Dahai Yue ${ }^{2,3} \cdot$ Ninez A. Ponce ${ }^{3,4}$
}

Accepted: 21 July 2021 / Published online: 31 July 2021

(c) The Author(s), under exclusive licence to Springer Science+Business Media, LLC, part of Springer Nature 2021

\begin{abstract}
Latinxs are vulnerable to experiencing housing insecurity and less likely to receive public benefits, such as health insurance, which can impact a household's economic resources. We inform homelessness prevention by examining the association of social risks and healthcare access with housing insecurity for Latinxs. Our sample consisted of 120,362 participants under the age of 65 , of which $17.3 \%$ were Latinx. Weighted chi-squared tests and logistic regression were used to examine predictors of housing insecurity. Housing insecurity was measured as worry about paying for housing. Latinxs were almost twice as likely as non-Latinxs to worry about paying for housing. Excellent/fair health status, health service use, and having health insurance decreased the likelihood of housing insecurity for Latinxs. Access to health insurance, regardless of citizenship status, and use of preventative healthcare to maintain good health can be protective against housing insecurity.
\end{abstract}

Keywords Homelessness $\cdot$ Latinx $\cdot$ Housing insecurity $\cdot$ Immigrants $\cdot$ Healthcare

\section{Introduction}

Latinxs are highly vulnerable to experiencing housing insecurity. In the United States, Latinx households account for $21 \%$ of all renter households with extremely low incomes, meaning that they have incomes at or below the poverty line. In contrast, only $6 \%$ of White non-Latinx households are extremely low-income renters [1]. Further, in $201654 \%$ of Latinx households were estimated to be rent burdened, paying more than $30 \%$ of their incomes for housing, compared to $43 \%$ for the White non-Latinx population [2]. The

Melissa Chinchilla

mechinchilla@altamed.org

Dahai Yue

dhyue@umd.edu

Ninez A. Ponce

nponce@ucla.edu

1 AltaMed Health Services, Institute for Health Equity, 2040 Camfield Avenue, Los Angeles, CA 90040, USA

2 Department of Health Policy and Management, University of Maryland, 4200 Valley Drive, Suite 2242, College Park, MD 20742-2611, USA

3 UCLA Center for Health Policy Research, 10960 Wilshire Blvd \#1550, Los Angeles, CA 90024, USA

4 Department of Health Policy and Management, UCLA Fielding School of Public Health, Los Angeles, CA, USA combination of being low-income and rent burdened, means that many Latinx households are at the cusp of losing their housing. In fact, Latinxs make up $22 \%$ of the homeless population, higher than their share of the U.S. population, $18 \%$ [3]. The number of Latinxs experiencing homelessness is likely an undercount as Latinxs frequently exist outside of traditional homeless spaces, rely heavily on social networks, and use public services at lower rates than other racial/ethnic groups [4]. The economic fallout due to COVID-19 and its disproportional impacts on Latinxs [5] could threaten Latinxs' ability to pay for housing. Thus, investigating predictors of housing insecurity can inform policy levers to prevent people from the cascade of events that lead to housing instability and homelessness.

Previous studies suggest that Latinxs are vulnerable to experiencing housing insecurity $[6,7]$ and less likely to receive public benefits, such as health insurance, which can impact a household's economic resources [8-10]. Latinxs experience the double jeopardy of lower insurance coverage and higher rates of chronic conditions, notably obesity [11] and diabetes [12]. Housing insecurity can have direct effects on individual health including poor health status [13], psychological distress [14], and developmental risk among children [15]. Negative health outcomes are also associated with lower earnings [16, 17], and chronic illness is documented to have direct effects on housing stability [18]. When combined with financial strain, negative health status and the 
use of healthcare services can impact an individual's housing stability [19]. Low-income households are more prone to experience financial hardships due to ill-health and chronic disease, spending a higher proportion of income on medical care [20]. Out of pocket medical costs can be financially devastating, particularly when combined with other crises such as a loss of household income [21]. Having health insurance can be a protective factor against housing insecurity, minimizing out of pocket expenses and encouraging service use that leads to improvements in health status. Analysis of Medicaid expansion in California has demonstrated a relationship between increases in health insurance rates and lower evictions at the county level [22].

Access to healthcare, however, is conditioned by citizenship/immigration status. The nearly 60 million Latinxs in the United States [23] are a heterogeneous population, which includes native, as well as, foreign born individuals; each group facing its own unique challenges. In the U.S., about $35 \%$ of Latinxs are foreign-born, $22 \%$ of which are not naturalized citizens (24). Foreign-born Latinxs are three times as likely to lack a high school degree than native-born Latinxs and have lower median earnings [25]. Non-citizens include lawfully present residents and undocumented immigrants. The Pew Research Center estimates that 10.5 million immigrants in the U.S. are undocumented [26]. Noncitizens are more likely to be forced to move than citizens because they cannot afford to pay rent and may not qualify for housing support when they experience periods of decreased income [27]. These individuals are also less likely to use public services and often feel stigmatized by public discourse that characterizes them as "drains" on public resources [28-30].

Minimal attention has been paid to what may be early indicators of housing need or factors that may prevent housing instability for Latinxs. Our paper uses nationally representative data to examine factors associated with housing insecurity for Latinxs- including non-citizens-specifically the potential role of socio-economic characteristics, health status, health insurance access, and the use of health services.

\section{Methods}

Data from the National Health Interview Survey (NHIS) 2013-2017 were used to assess the relationship between socio-economic characteristics, health status, use of health services, and housing insecurity. NHIS is a cross-sectional national survey of the civilian non-institutionalized population in the United States. The survey assesses the rate, distribution, and effects of illness and disability, as well as, use of health services. NHIS also offers insights into the social determinants of health, including socio-economic characteristics, and provides data at multiple levels including person, family, and household [31]. The University of California Los Angeles (UCLA) General Institutional Review Board (IRB) reviewed this study and determined that neither certification of exemption from UCLA IRB review nor UCLA IRB approval of the proposed activities was required. NHIS is a de-identified, publicly available dataset and does not constitute human subjects research.

\section{Participants}

NHIS 2013-2017 sample adult data were combined with person, family, and household level data. The sample consisted of 120,362 participants under the age of 65 . The sample was $17.4 \%(n=20,674)$ Latinx, of which $33.4 \%$ $(\mathrm{n}=7114)$ reported being non-citizens. Non-citizens included those who have legal status in the U.S. as well as undocumented individuals.

\section{Independent Variables}

Socio-economic factors of interest consisted of citizenship status (i.e., citizen versus non-citizen), age, gender, whether or not an individual was married or in a relationship (i.e., partnered), number of children, income, employment, and educational status. We also examined whether the respondent reported living with more than one family in the household, which can be a potential coping mechanism for a lack of housing affordability.

Use of health services was assessed through various factors including whether or not the participant had a usual source of care and health insurance. In addition, use of health services consisted of number of hospital visits and whether or not an individual visited an emergency room in the past 12 months.

Health status was characterized by whether or not the participant reported a functional limitation (e.g., eating, bathing, dressing, or getting around inside their home) or limitation of daily activities (i.e., any limitation) due to physical, mental, or emotional problems. Health status was also evaluated using self-reported health and whether or not the participant received Social Security Insurance (SSI).

\section{Outcome Measure}

One outcome measure was used as a proxy for housing insecurity: whether the respondent reported being worried about paying for housing at the time the survey was conducted.

\section{Statistical Analysis}

Weighted chi-squared tests and survey weighted logistic regression were used to examine predictors of housing insecurity. We conducted analyses separately for the overall 
sample, Latinxs, and non-citizen Latinxs. All analyses utilized a sample with imputed data. A total of $70.3 \%$ participants had no missing data. For missing observations, we imputed data using ten sets of chained multiple imputation; a data augmentation algorithm used to fill missing data by drawing from a multivariate normal distribution given the observed data. Chained multiple imputation is shown to be reliable given sufficient sample size, even when normality assumptions are violated [32]. For all predictive variables, a single summary score of effects (i.e., odds ratio) is reported. A p-value $<0.05$ was chosen to assess significance. All statistical analyses were performed using Stata MP 15.1.

\section{Results}

There were a number of significant differences between Latinx and non-Latinx sample populations (Table 1). Latinxs had a greater proportion of non-citizens $(33.4 \%$ versus $4.6 \%$ ), were more likely to be $18-26$ years of age ( $23.9 \%$ versus $18.6 \%$ ), were slightly less likely to be female ( $49.3 \%$ versus $51.2 \%$ ), were more likely to have children (57.4\% versus $38.8 \%$ ), and more likely to have lower levels of education (29.4\% versus $7.7 \%$ less than high school) and income (38.7\% versus $26.2 \%$ earning less than $\$ 35,000$ a year). Latinxs were also slightly more likely to report being unemployed (5.9\% versus 5.1\%) and less likely to be living with more than one family in the household $(2.6 \%$ versus $3.1 \%$ ). With regards to health status and use of health services, Latinxs were more likely to be uninsured $(30.7 \%$ versus $11.1 \%$ ), were almost twice as likely to use clinics as their usual source of care (38.7\% versus $21.9 \%$ ) and were less likely to report functional limitations $(1.1 \%$ versus $1.4 \%)$ or limitations in daily activities (8.0\% versus $12.7 \%$ ).

Latinxs reported fewer hospital visits $(30.6 \%$ versus $18.4 \%$ with zero visits), but slightly higher rates of "poor" (versus "excellent/ fair") health (11.8\% versus $10.6 \%)$. Latinxs were also less likely to have an emergency department visit (16.5\% versus $18.4 \%)$ and slightly less likely to receive SSI (2.1\% versus $2.7 \%$ ). With regards to outcome of interest, Latinxs were more likely to be worried about paying for housing (39.8\% versus $22.8 \%$ ) when compared to the non-Latinx population.

There were a number of significant differences between Latinx citizens and Latinx non-citizens (Table 2). Non-citizens were more likely to be of working age (i.e., 27-54 years of age), to earn below $\$ 35,000$ (52.3\% versus $31.9 \%)$, have lower levels of education $(53.0 \%$ versus $17.6 \%$ with less than high school), to be partnered ( $71.0 \%$ versus $55.2 \%)$, and to have children $(67.9 \%$ versus $51.9 \%)$. Non-citizen Latinx were slightly less likely to be female ( $47.8 \%$ versus $50.0 \%)$ and were more likely to live in a household with more than one family (3.6\% versus $2.1 \%)$ when compared to citizen Latinxs.

While reporting no significant differences with regard to self-reported health, non-citizens were less likely to be insured $(55.8 \%$ versus $18.0 \%)$, more likely to use clinics as their usual source of care (59.3\% versus $30.7 \%)$, and to report zero hospital visits (43.6\% versus $24.0 \%$ ). Non-citizen Latinx were also less likely to have an ER visit (13.5\% versus $18.0 \%)$, to report functional limitations $(0.6 \%$ versus $1.3 \%)$, limitations of daily activities ( $4.5 \%$ versus $9.9 \%)$, and to receive SSI $(0.7 \%$ versus $2.9 \%)$ when compared to citizen Latinxs. With regards to housing insecurity, non-citizen Latinxs were more likely to report being worried about paying for housing $(52.5 \%$ versus $33.4 \%)$.

\section{Multivariate Regression}

An analysis of all participants, regardless of Latinx ethnicity, highlights several significant factors associated with being worried about paying for housing (Table 3). Notably, being Latinx was associated with increased odds of being worried about paying for housing by a factor of 1.55 , while not being a U.S. citizen increased an individual's odds by 1.34 . Regression analysis also suggests that age (i.e., over 26 years of age), being female, and having children all increased one's chances of being worried about paying for housing, while making more than $\$ 35,000$, and having more than a high school education decreased one's chances. Being employed was also associated with a decreased odds of 0.55 of being worried about paying for housing, and not working and not looking for work decreased odds by a factor of 0.38 . Living in a household with more than one family decreased odds by 0.80 .

Logistic regression for all respondents also showed that reporting at least one ER visit in the past 12 months was associated with increased odds of being worried about paying for housing by a factor of 1.25 and having more than 6 hospital visits was also associated with a slight increase by a factor of 1.14. In contrast, having 1 hospital visit slightly decreased odds by a factor of 0.91 . Excellent/fair health was associated with a decreased odds of 0.57 , whereas limitations in daily activities was associated with increased odds of 1.40 of reporting being worried about paying for housing. Lastly, having health insurance (both private and public) and receiving SSI were associated with decreased odds of being worried about paying for housing.

\section{Latinx Subsample}

For the Latinx sample, not being a U.S. citizen was associated with increased odds of 1.39 of reporting being worried about paying for housing. Age (i.e., over 26 years of age), being female, having a partner, and having children all increased 
Table 1 Sample characteristics with weighted proportions, all respondents, stratified by Latinx ethnicity

\begin{tabular}{|c|c|c|}
\hline Variable & $\begin{array}{l}\text { Non-Latinx } \\
\mathrm{n}(\%)\end{array}$ & $\begin{array}{l}\text { Latinx } \\
\text { n (\%) }\end{array}$ \\
\hline Total sample & $99,688(82.59)$ & $20,674(17.41)$ \\
\hline Housing worry*** & $23,587(22.81)$ & $8787(39.81)$ \\
\hline \multicolumn{3}{|l|}{ Socio-economic characteristics } \\
\hline Non-citizens ${ }^{* * *}$ & $4474(4.63)$ & $7114(33.40)$ \\
\hline \multicolumn{3}{|l|}{ Age*** } \\
\hline $18-26$ & $15,650(18.60)$ & $4041(23.90)$ \\
\hline $27-34$ & $17,384(16.90)$ & $4516(21.10)$ \\
\hline $35-44$ & $19,578(19.80)$ & $5374(23.60)$ \\
\hline $45-54$ & $22,186(22.40)$ & $3995(18.90)$ \\
\hline $55-64$ & $24,890(22.30)$ & $2748(12.40)$ \\
\hline Female $* * *$ & $53,420(51.20)$ & $11,365(49.30)$ \\
\hline Partnered & $51,322(61.10)$ & $11,289(60.70)$ \\
\hline Children*** & $34,180(38.80)$ & $11,243(57.40)$ \\
\hline \multicolumn{3}{|l|}{ Income*** } \\
\hline Below $\$ 35 \mathrm{~K}$ & $32,093(26.20)$ & $9528(38.70)$ \\
\hline$\$ 35-\$ 75 \mathrm{~K}$ & $27,416(28.70)$ & $6201(35.30)$ \\
\hline Above $\$ 75 \mathrm{~K}$ & $34,026(45.10)$ & $3591(26.00)$ \\
\hline \multicolumn{3}{|l|}{ Employment status $* * *$} \\
\hline Unemployed & $4900(5.13)$ & $1240(5.87)$ \\
\hline Employed & $71,810(72.40)$ & $14,385(70.30)$ \\
\hline Not working and not looking for employment work & $22,934(22.50)$ & $5042(23.80)$ \\
\hline \multicolumn{3}{|l|}{ Education level $* * *$} \\
\hline Less than high school & 7589 (7.69) & $6365(29.40)$ \\
\hline High school & $23,296(23.79)$ & $5342(27.30)$ \\
\hline More than high school & $68,349(68.60)$ & $8623(43.40)$ \\
\hline More than one family household ${ }^{* *}$ & $4793(3.12)$ & $860(2.60)$ \\
\hline \multicolumn{3}{|l|}{ Access and use of health services } \\
\hline \multicolumn{3}{|l|}{ Health insurance*** } \\
\hline No insurance & $11,338(11.10)$ & $6384(30.70)$ \\
\hline Private & $67,973(74.60)$ & $9204(49.90)$ \\
\hline Public & $15,010(14.30)$ & $3910(19.40)$ \\
\hline \multicolumn{3}{|l|}{ Usual source of care ${ }^{* * *}$} \\
\hline Clinic & $22,268(21.90)$ & $6296(38.70)$ \\
\hline Doctor's office & $58,442(74.50)$ & $8111(56.80)$ \\
\hline Emergency room & $1161(1.26)$ & $273(1.63)$ \\
\hline Other & $2344(2.40)$ & $449(2.79)$ \\
\hline \multicolumn{3}{|l|}{ Visit with doctor or health professional $* * *$} \\
\hline 0 & $18,320(18.40)$ & $6356(30.60)$ \\
\hline 1 & $19,283(20.00)$ & $4144(21.10)$ \\
\hline $2-3$ & $26,797(27.40)$ & $4741(23.30)$ \\
\hline $4-5$ & $12,805(12.80)$ & $2080(9.81)$ \\
\hline $6+$ & $22,483(21.40)$ & $3353(15.30)$ \\
\hline ER visit (at least 1 ) $* * *$ & $19,224(18.40)$ & $3623(16.50)$ \\
\hline \multicolumn{3}{|l|}{ Health Status } \\
\hline Functional limitations* & $1567(1.40)$ & $285(1.07)$ \\
\hline Limitation of activities*** & $14,746(12.70)$ & $1964(8.01)$ \\
\hline Social Security Insurance** & $3378(2.67)$ & $573(2.13)$ \\
\hline \multicolumn{3}{|l|}{ Self-reported health $* * *$} \\
\hline Poor & $12,043(10.60)$ & $2729(11.80)$ \\
\hline Excellent/fair & $87,610(89.40)$ & $17,938(88.20)$ \\
\hline
\end{tabular}

Pearson's Chi-squared test compared the weighted proportions for Latinx citizen versus non-citizen: $\mathrm{p}<0.001^{* * *}, \mathrm{p}<0.01^{* *}, \mathrm{p}<0.05^{*}$ 
Table 2 Sample characteristics with weighted proportions, Latinx respondents, stratified by citizenship

\begin{tabular}{|c|c|c|}
\hline Variable & $\begin{array}{l}\text { Latinx citizen } \\
n(\%)\end{array}$ & $\begin{array}{l}\text { Latinx non- } \\
\text { citizen } n(\%)\end{array}$ \\
\hline Total sample & $13,462(66.60)$ & $7114(33.40)$ \\
\hline Housing worry*** & $4815(33.38)$ & $3925(52.54)$ \\
\hline \multicolumn{3}{|l|}{ Socio-economic characteristics } \\
\hline \multicolumn{3}{|l|}{ Age $* * *$} \\
\hline $18-26$ & $3106(28.40)$ & $918(15.10)$ \\
\hline $27-34$ & $2754(19.40)$ & $1734(24.50)$ \\
\hline $35-44$ & $2987(20.00)$ & $2352(30.60)$ \\
\hline $45-54$ & $2550(18.30)$ & $1433(20.40)$ \\
\hline $55-64$ & $2065(13.90)$ & $677(9.48)$ \\
\hline Female* & $7545(50.00)$ & $3763(47.80)$ \\
\hline Partnered $* * *$ & $6555(55.20)$ & $4654(71.00)$ \\
\hline Children*** & $6524(51.90)$ & $4647(67.90)$ \\
\hline \multicolumn{3}{|l|}{ Income $* * *$} \\
\hline Below $\$ 35 \mathrm{~K}$ & $5322(31.90)$ & $4169(52.30)$ \\
\hline$\$ 35-75 \mathrm{~K}$ & $4206(35.10)$ & $1977(35.70)$ \\
\hline Above $\$ 75 \mathrm{~K}$ & $3080(33.10)$ & $507(12.00)$ \\
\hline \multicolumn{3}{|l|}{ Employment status $* * *$} \\
\hline Unemployed & $837(6.30)$ & $400(5.05)$ \\
\hline Employed & $9458(70.70)$ & $4861(69.50)$ \\
\hline Not working and not looking for work employment & $3164(23.00)$ & $1850(25.50)$ \\
\hline \multicolumn{3}{|l|}{ Education Level*** } \\
\hline Less than high school & $2515(17.60)$ & $3802(53.00)$ \\
\hline High school & $3615(27.60)$ & $1707(26.60)$ \\
\hline More than high school & $7236(54.70)$ & $1370(20.40)$ \\
\hline More than one family in household*** & $462(2.12)$ & $396(3.60)$ \\
\hline \multicolumn{3}{|l|}{ Access and use of health services } \\
\hline \multicolumn{3}{|l|}{ Health insurance*** } \\
\hline No insurance & $2447(18.00)$ & $3890(55.80)$ \\
\hline Private & $7358(60.60)$ & $1820(28.90)$ \\
\hline Public & $2907(21.50)$ & $993(15.30)$ \\
\hline \multicolumn{3}{|l|}{ Usual source of care*** } \\
\hline Clinic & $3541(30.70)$ & $2725(59.30)$ \\
\hline Doctor's office & $6650(65.20)$ & $1438(35.40)$ \\
\hline Emergency room & $168(1.39)$ & $105(2.27)$ \\
\hline Other & $325(2.70)$ & $124(3.05)$ \\
\hline \multicolumn{3}{|l|}{ Visit with doctor or health professional $* * *$} \\
\hline 0 & $3219(24.00)$ & $3099(43.60)$ \\
\hline 1 & $2695(21.60)$ & $1430(20.00)$ \\
\hline $2-3$ & $3453(25.90)$ & $1264(18.10)$ \\
\hline $4-5$ & $1529(10.90)$ & $544(7.74)$ \\
\hline $6+$ & $2566(17.70)$ & $777(10.50)$ \\
\hline ER visit (at least 1 )*** & $2653(18.00)$ & $957(13.50)$ \\
\hline \multicolumn{3}{|l|}{ Health status } \\
\hline Functional limitations*** & $245(1.32)$ & $40(0.61)$ \\
\hline Limitation of activities*** & $1625(9.86)$ & $338(4.45)$ \\
\hline Social Security Insurance $* * *$ & $519(2.87)$ & $54(0.70)$ \\
\hline \multicolumn{3}{|l|}{ Self-reported health } \\
\hline Poor & $1824(11.60)$ & $898(12.20)$ \\
\hline Excellent/Fair & $11,634(88.40)$ & $6213(87.80)$ \\
\hline
\end{tabular}

Pearson's Chi-squared test compared the weighted proportions for Latinx citizen versus non-citizen: $\mathrm{p}<0.001^{* * *}, \mathrm{p}<0.01^{* *}, \mathrm{p}<0.05^{*}$ 
Table 3 Predictors of worry about paying for housing, weighted odds ratios $(\mathrm{OR})$ and confidence intervals $(\mathrm{CI})$

\begin{tabular}{|c|c|c|c|}
\hline Total sample & $\begin{array}{l}\text { All respondents } \\
120,362\end{array}$ & $\begin{array}{l}\text { Latinxs } \\
120,099\end{array}$ & $\begin{array}{l}\text { Latinxs non-citizen } \\
20,401\end{array}$ \\
\hline Variable & $\mathrm{OR}(\mathrm{CI})$ & $\mathrm{OR}(\mathrm{CI})$ & $\mathrm{OR}(\mathrm{CI})$ \\
\hline \multicolumn{4}{|l|}{ Socio-economic characteristics } \\
\hline Constant & $1.30(1.08-1.57)^{* *}$ & $1.86(1.28-2.70)^{* *}$ & $3.20(1.66-6.17)^{* *}$ \\
\hline Latinx & $1.55(1.47-1.64)^{* * *}$ & & \\
\hline Non-Citizen & $1.34(1.24-1.44)^{* * *}$ & $1.39(1.25-1.54)^{* * *}$ & \\
\hline \multicolumn{4}{|l|}{ Age } \\
\hline \multicolumn{4}{|l|}{$18-26$} \\
\hline $27-34$ & $1.55(1.44-1.66)^{* * *}$ & $1.85(1.60-2.13)^{* * *}$ & $1.78(1.38-2.31)^{* * *}$ \\
\hline $35-44$ & $2.01(1.87-2.15)^{* * *}$ & $2.12(1.86-2.41)^{* * *}$ & $1.76(1.40-2.22)^{* * *}$ \\
\hline $45-54$ & $2.33(2.17-2.50)^{* * *}$ & $2.40(2.08-2.77)^{* * *}$ & $2.00(1.54-2.60)^{* * *}$ \\
\hline $55-64$ & $1.76(1.63-1.90)^{* * *}$ & $2.34(2.00-2.75)^{* * *}$ & $1.99(1.47-2.70)^{* * *}$ \\
\hline Female & $1.20(1.16-1.25)^{* * *}$ & $1.14(1.05-1.23)^{* *}$ & $1.11(0.95-1.29)$ \\
\hline Partnered & $0.99(0.95-1.04)$ & $1.15(1.05-1.26)^{* *}$ & $1.24(1.06-1.46)^{*}$ \\
\hline Children & $1.31(1.25-1.37)^{* * *}$ & $1.22(1.10-1.35)^{* * *}$ & $1.24(1.07-1.44)^{* *}$ \\
\hline \multicolumn{4}{|l|}{ Income } \\
\hline \multicolumn{4}{|l|}{ Below $\$ 35 \mathrm{~K}$} \\
\hline$\$ 35-75 \mathrm{~K}$ & $0.70(0.66-0.73)^{* * *}$ & $0.67(0.60-0.75)^{* * *}$ & $0.61(0.52-0.72)^{* * *}$ \\
\hline Above $\$ 75 \mathrm{~K}$ & $0.35(0.33-0.37)^{* * *}$ & $0.39(0.34-0.45)^{* * *}$ & $0.37(0.28-0.49)^{* * *}$ \\
\hline \multicolumn{4}{|l|}{ Employment status } \\
\hline \multicolumn{4}{|l|}{ Unemployed } \\
\hline Employed & $0.55(0.50-0.60)^{* * *}$ & $0.61(0.50-0.74)^{* * *}$ & $0.63(0.42-0.94)^{*}$ \\
\hline $\begin{array}{l}\text { Not working and not looking for } \\
\text { work employment }\end{array}$ & $0.38(0.35-0.42)^{* * *}$ & $0.43(0.35-0.52)^{* * *}$ & $0.48(0.32-0.73)^{* *}$ \\
\hline \multicolumn{4}{|l|}{ Education level } \\
\hline \multicolumn{4}{|l|}{ Less than high school } \\
\hline High school & $1.00(0.94-1.07)$ & $1.03(0.93-1.15)$ & $1.18(1.00-1.39)$ \\
\hline More than high school & $0.88(0.83-0.94)^{* * *}$ & $0.89(0.80-0.99)^{*}$ & $0.96(0.80-1.16)$ \\
\hline More than one family in household & $0.80(0.71-0.89)^{* * *}$ & $0.84(0.68-1.03)$ & $0.77(0.57-1.04)$ \\
\hline \multicolumn{4}{|l|}{ Use of health services } \\
\hline \multicolumn{4}{|l|}{ Health insurance } \\
\hline \multicolumn{4}{|l|}{ No insurance } \\
\hline Public & $0.74(0.69-0.80)^{* * *}$ & $0.87(0.76-0.97)^{*}$ & $0.93(0.75-1.15)$ \\
\hline Private & $0.49(0.46-0.52) * * *$ & $0.61(0.54-0.69)^{* * *}$ & $0.63(0.52-0.76)^{* * *}$ \\
\hline \multicolumn{4}{|l|}{ Usual source of care } \\
\hline Clinic & $0.95(0.82-1.10)$ & $0.81(0.60-1.10)$ & $0.66(0.39-1.10)$ \\
\hline Doctor's office & $0.91(0.79-1.05)$ & $0.68(0.51-0.91)^{*}$ & $0.58(0.34-0.97)^{*}$ \\
\hline Emergency room & $1.08(0.88-1.34)$ & $0.83(0.54-1.27)$ & $0.90(0.45-1.80)$ \\
\hline \multicolumn{4}{|l|}{ Other } \\
\hline \multicolumn{4}{|l|}{ Visit with doctor or health professional } \\
\hline \multicolumn{4}{|l|}{0} \\
\hline 1 & $0.91(0.85-0.96)^{* *}$ & $0.90(0.80-1.02)$ & $1.06(0.88-1.29)$ \\
\hline $2-3$ & $0.99(0.93-1.05)$ & $1.01(0.89-1.15)$ & $1.16(0.95-1.41)$ \\
\hline $4-5$ & $1.03(0.96-1.12)$ & $1.00(0.86-1.18)$ & $1.06(0.80-1.41)$ \\
\hline $6+$ & $1.14(1.07-1.22) * * *$ & $1.14(0.98-1.31)$ & $1.07(0.83-1.38)$ \\
\hline ER visit (at least 1 ) & $1.25(1.19-1.31)^{* * *}$ & $1.17(1.03-1.32)^{*}$ & $1.13(0.93-1.39)$ \\
\hline \multicolumn{4}{|l|}{ Health status } \\
\hline Functional limitations & $0.92(0.80-1.06)$ & $0.83(0.57-1.22)$ & $0.95(0.38-2.42)$ \\
\hline Limitation of activities & $1.40(1.30-1.50)^{* * *}$ & $1.33(1.11-1.59)^{* *}$ & $1.27(0.86-1.87)$ \\
\hline Social security insurance & $0.67(0.60-0.74) * * *$ & $0.73(0.56-0.95)^{*}$ & $1.01(0.50-2.04)$ \\
\hline Self-reported health & & & \\
\hline
\end{tabular}


Table 3 (continued)

\begin{tabular}{llll}
\hline Total sample & All respondents & Latinxs & Latinxs non-citizen \\
& 120,362 & 120,099 & 20,401 \\
Variable & OR $(\mathrm{CI})$ & OR $(\mathrm{CI})$ & OR $(\mathrm{CI})$ \\
\hline Poor & & & \\
Excellent/fair & $0.57(0.54-0.61)^{* * *}$ & $0.53(0.46-0.60)^{* * * *}$ & $0.48(0.39-0.60)^{* * *}$ \\
\hline $\mathrm{p}<0.001^{* * *}, \mathrm{p}<0.01^{* *}, \mathrm{p}<0.05^{*}$ & & &
\end{tabular}

the odds that Latinxs reported being worried about paying for housing (Table 3 ). Having more than a high school education decreased odds of being worried about paying for housing by a factor of 0.89 . Not working and not looking for work decreased the odds of being worried about paying for housing by 0.43 , whereas being employed decreased odds by a factor of 0.61 . Having an income above $\$ 35,000$ also decreased the odds of housing worry.

For the Latinx sample, having private or public health insurance was associated with reduced odds of reporting being worried about paying for housing. Listing a doctor's office as one's usual source of care was also associated with decreased odds of being worried about paying for housing by a factor of 0.68. For Latinxs, number of hospital visits was not a significant predictor; however, having at least one ER visit was significantly associated with increased odds of being worried about paying for housing by a factor of 1.17. Reporting excellent/fair health was associated with decreased odds that an individual was worried about paying for housing by a factor of 0.53 , while experiencing limitations in daily activities was associated with increased odds of 1.33. Lastly, having SSI decreased odds by a factor of 0.73 .

\section{Non-citizen Latinx Subsample}

Among non-citizen Latinxs, age (i.e., over 26 years of age), having a partner, and having children were all associated with increased odds of being worried about paying for housing (Table 3). Having an income above $\$ 35,000$ and being employed or not working and not looking for work, were also associated with decreased odds of reporting being worried about paying for housing. Furthermore, using a doctor's office as one's usual source of care was associated with 0.58 decreased odds of reporting being worried about paying for housing, having private health insurance was associated with a 0.63 decrease, and reporting excellent/fair health was associated with 0.48 decreased odds.

\section{Discussion}

In 2017, Latinxs accounted for $18 \%$ of the total population but $27 \%$ of those living in poverty [33], placing a large segment of this population at the precipice of housing instability. In our analysis, we found that Latinxs were almost twice as likely as non-Latinxs to worry about paying for housing. Lower socioeconomic status and self-reported poor health among Latinxs was strongly associated with housing insecurity, especially among Latinxs non-citizens. Increased health access (i.e., health insurance) and health utilization (i.e., doctor's office as usual source of care) was associated with a decreased likelihood that Latinxs reported such worry. Our study highlights the potential role of health access in preventing housing instability, including homelessness, among Latinxs, a catastrophic outcome in people's lives that is associated with subsequent consumption of expensive health care services [34, 35].

Housing instability is particularly concerning for noncitizens. Within the Latinx sample, being a non-citizen increased one's odds of being worried about paying for housing. A pattern of economic vulnerability is frequently prevalent among immigrant populations when compared to native born individuals. Immigrants are more likely to dedicate a higher proportion of their income to housing costs [36], to report being unable to pay for housing [37], and to report having to move in with others due to housing expenses [37]. Non-citizens were also less likely to have health insurance and more likely to report no hospital visits. These patterns may be a result of an inability to obtain health insurance and minimal resources to seek medical care. Research suggests that, even with insurance expansion through the Affordable Care Act (ACA), unauthorized immigrants continue to experience notable challenges accessing health insurance [38]. Further, individuals with limited economic means are frequently required to make trade-offs, including dedicating more resources to housing and fewer to health-promoting resources [39, 40].

Unaffordable housing is associated with poorer self-rated health [41], and postponement of medical services [14, 42]. Our analysis shows that for non-citizen Latinxs, reporting excellent/fair health was associated with a decreased probability of being worried about paying for housing, while having private insurance and using a doctor's office as one's usual source of care was also associated with decreases in worry about paying for housing. This association may be due to the high correlation between income and access to private health insurance [43]. A supplemental analysis of insured and uninsured respondents showed significant 
differences between these two populations (Supplemental Table 1). Respondents who were insured were more likely to be employed, have higher incomes, have more than a high school education, and were less likely to report being worried about paying for housing than uninsured respondents. For non-citizen Latinxs, the relationship between public insurance and being worried about paying for housing was not statistically significant, which may be the result of a lower likelihood of receiving public health insurance [38] and potentially the greater financial need that this population experiences. In addition, having a doctor's office as a usual source of care was associated with a decrease in being worried about paying for housing for both Latinx respondents and Latinx non-citizens, but not the entire sample. Previous research has demonstrated that having a regular doctor has a greater impact on health outcomes than having a regular health care site [44]. The relationship between Latinxs and their doctors may be unique in its ability to impact social needs. For example, early research indicates that Latinx individuals may be more likely to identify as experiencing homelessness in health care settings where they trust who they are interacting with [45]. Notably, number of hospital visits and use of ER services were not significant predictors of housing insecurity for non-citizen Latinxs. This may be due to the significantly lower rates of usage of these services by immigrant populations [27].

Across all three samples, health insurance and excellent/ fair health were associated with decreases in being worried about paying for housing. However, the magnitude of the association between health insurance and being worried about paying for housing decreases slightly when comparing the Latinx population versus all respondents. Yet, our study still suggests a significant effect of health insurance on protecting housing stability for Latinxs. Generally, health insurance is closely linked to housing stability and financial security, with the loss of health insurance showing an association with decreased credit scores [46] and increased rates of eviction [47].

Our findings imply that policies beyond health insurance should also be considered to prevent housing instability for the Latinx population. Further, a greater focus is needed on the non-citizen population which shows a weaker correlation between access to health insurance and being worried about housing. Previous research suggests that immigration status, specifically being undocumented, leads to greater hardships identifying and maintaining housing, including an inability to qualify for federal housing subsidies [48] and local ordinances that prohibit landlords from renting to undocumented immigrants [49]. The Public Charge rule, effective February 2020, also blocked immigrant pathways to obtaining a green card if an immigrant is deemed reliant on federal assistance to food, health care and housing. Although there have been several district court decisions on injunctions and stays of the rule, the rule is likely to have a net chilling effect that adversely affects the housing stability of Latinx and their willingness to seek public benefits [50]. A supplemental analysis also showed that Latinx non-citizens are significantly more vulnerable than non-citizens that do not identify as Latinx. Latinx non-citizens are more likely to worry about paying for housing, to report incomes below $\$ 35,000$ a year, to have less than a high school education, to have no health insurance, report fewer visits to a doctor or health professional, and are more likely to report poor health (Supplemental Table 2).

\section{Limitations}

This study had limitations. First, NHIS is a household survey and does not capture homeless or institutionalized individuals. In this study, housing insecurity was defined by one NHIS survey response, whether the respondent was worried about paying for housing. This measure served as proxy for housing insecurity and the likelihood of experiencing homelessness. Second, analyses examined the potential impact of non-citizenship status on housing insecurity. However, the non-citizenship category did not capture authorized status in the U.S. Therefore, it was not possible to examine differences between undocumented, U.S. residents, or visa holders, all of which fall under the category of non-citizen but may have differing socio-economic characteristics and access to public resources. Third, NHIS consists of self-reported data. In general, self-reported data can present challenges with internal validity as data may be impacted by recall or desirability bias. Fourth, NHIS data includes restricted geographic information. The only variable publicly available is region, which is an aggregate of states by western, eastern, southern, and northern regions. Information aggregated at the region level provides limited added value to our analyses as it is unable to account for key state differences, such as state Medicaid expansion. Lower levels of geography are restricted due to potential disclosure risks. Lastly, NHIS is a cross-sectional dataset and causality bias cannot be ruled out. Housing affordability has a number of direct and indirect pathways to health. For example, unaffordable housing is associated with trade-offs that may harm health [51], and an individual's health impacts housing affordability by affecting earnings $[52,53]$. Cross-sectional data cannot be used to determine the direction of the relationship. Despite limitations, our study offers important insights into the association between housing instability and health and looks at a minimally studied population-Latinxs. 


\section{Conclusions}

Our analyses suggest that being Latinx and being a noncitizen was associated with increased worry about paying for housing. For Latinxs, having at least one emergency department visit increased the likelihood that a participant was worried about paying for housing. Identifying Latinxs through ER services may then be an opportunity to assess and connect individuals to housing resources. Latinx households reporting a doctor's office as one's usual source of care were less likely to report being worried about paying for housing, which suggests that there may be something unique about the patient-doctor relationship that is protective for the Latinx population. Future research should look to explore how doctor-patient relationships may impact social needs. Further, Latinxs experiencing housing insecurity can potentially be identified through clinic visits, as both citizen and non-citizen Latinxs are more likely to use clinics as their usual source of care. While not significantly associated with housing instability, clinics can be particularly helpful for targeting non-citizens in need of housing resources, as non-citizen Latinxs use clinics at higher rates than citizens. Consequently, homeless prevention may focus on the role of clinics in identifying early indicators of housing need and facilitating social service connection.

For all participants, regardless of ethnicity or citizenship status, having health insurance and reporting excellent/fair health were protective factors against housing insecurity, which highlights the potential impact of public health insurance expansion on housing outcomes. Preventive healthcare can help individuals maintain good health, while insurance coverage allows individuals to use preventive services instead of waiting to obtain care once their health has deteriorated. Research on the ACA has shown increased rates of eviction in states that did not expand medical insurance coverage [47]. The number of Latinx living in the non-expansion states in 2018 was over 22 million (54). Increasing the availability of health insurance will be pivotal given local and national concerns, particularly as evictions have risen during the COVID-19 pandemic.

Pearson's Chi-squared test compared the weighted proportions for Latinx versus non-Latinx: $\mathrm{p}<0.001 * * *$, $\mathrm{p}<0.01^{* *}, \mathrm{p}<0.05^{*}$

Supplementary Information The online version contains supplementary material available at https://doi.org/10.1007/s10903-021-01258-9.

\section{References}

1. Aurand A, Emmanuel D, Yentel D, Errico E, Pang M. The gap: A shortage of affordable homes. Washington, DC: National Low Income Housing Coalition; 2017.

2. Renter cost burdens by race and ethnicity (1B). Joint center for housing studies. https://www.jchs.harvard.edu/ARH_2017_cost_ burdens_by_race. Accessed 19 Nov 2020.

3. HUD. The 2018 annual homeless assessment report (AHAR) to congress, part 1: point-in-time estimates of homelessness. Washington, D.C.: HUD; 2018. p. 100.

4. Conroy SJ, Heer DM. Hidden hispanic homelessness in Los Angeles: the "Latino paradox" revisited. Hisp J Behav Sci. 2003;25(4):530-8.

5. CDC COVID data tracker. https://www.cdc.gov/covid-data-track er/index.html\#demographics. Accessed 27 July 2020

6. Massey DS, Durand J, Malone NJ. Beyond smoke and mirrors: Mexican immigration in an era of economic integration. New York: Russell Sage Foundation; 2002.

7. Passel JS, Director PT, Lopez MH. A portrait of unauthorized immigrants in the United States. Washington, DC: Pew Research Center; 2009.

8. Alegria M, Cao Z, McGuire TG, Ojeda VD, Sribney B, Woo M, et al. Health insurance coverage for vulnerable populations. Inq $\mathbf{J}$ Med Care Organ Provis Financ. 2006;43(3):231-54.

9. Doty MM, Blumenthal D, Collins SR. The affordable care act and health insurance for Latinos. JAMA. 2014;312(17):1735-6.

10. Joseph TD, Marrow HB. Health care, immigrants, and minorities: lessons from the affordable care act in the U.S. J Ethn Migr Stud. 2017;43(12):1965-84.

11. Pawson IG, Martorell R, Mendoza FE. Prevalence of overweight and obesity in US Hispanic populations. Am J Clin Nutr. 1991;53(6):1522S-1528S.

12. Schneiderman N, Llabre M, Cowie CC, Barnhart J, Carnethon M, Gallo LC, et al. Prevalence of diabetes among hispanics/ Latinos from diverse backgrounds: the hispanic community health study/study of Latinos (HCHS/SOL). Diabetes Care. 2014;37(8):2233-9.

13. Stahre M, VanEenwyk J, Siegel P, Njai R. Housing insecurity and the association with health outcomes and unhealthy behaviors, Washington State, 2011. Prev Chronic Dis. 2015. https://doi.org/ 10.5888/pcd12.140511.

14. Pollack CE, Lynch J, Alley D, Cannuscio C. Foreclosure and health status. LDI Issue Brief. 2010;15(2):1-4.

15. Cutts DB, Meyers AF, Black MM, Casey PH, Chilton M, Cook JT, et al. US housing insecurity and the health of very young children. Am J Public Health. 2011;101(8):1508-14.

16. Halla M, Zweimüller M. The effect of health on earnings: Quasiexperimental evidence from commuting accidents. Labour Econ. 2013;24:23-38.

17. Prados MJ. Health and earnings inequality over the life cycle: the redistributive potential of health policies. New York: Manuscr Columbia Univ New York; 2012.

18. Charkhchi P, Fazeli Dehkordy S, Carlos RC. Housing and food insecurity, care access, and health status among the chronically ill: an analysis of the behavioral risk factor surveillance system. $\mathbf{J}$ Gen Intern Med. 2018;33(5):644-50.

19. Treglia D, Johns EL, Schretzman M, Berman J, Culhane DP, Lee DC, et al. When crises converge: hospital visits before and after shelter use among homeless New Yorkers. Health Aff (Millwood). 2019;38(9):1458-67.

20. Valtorta NK, Hanratty B. Socioeconomic variation in the financial consequences of ill health for older people with chronic diseases: a systematic review. Maturitas. 2013;74(4):313-33. 
21. McIntyre D, Thiede M, Dahlgren G, Whitehead M. What are the economic consequences for households of illness and of paying for health care in low-and middle-income country contexts? Soc Sci Med. 2006;62(4):858-65.

22. Allen HL, Eliason E, Zewde N, Gross T. Can medicaid expansion prevent housing evictions? Health Aff (Millwood). 2019;38(9):1451-7.

23. Census. ACS 1 year data 2018. American Community Survey. https://data.census.gov/cedsci/table?d=ACS\%205-Year\%20Est imates\%20Data\%20Profiles\&table=DP05\&tid=ACSDP5Y2018. DP05. Accessed 27 July 2020

24. U.S. Census. The hispanic population in the United States: 2019. Table 7. Nativity and citizenship status by sex, hispanic origin, and race. https://www.census.gov/data/tables/2019/demo/hispa nic-origin/2019-cps.html. Accessed 25 June 2019.

25. Burd-Sharps et al. A portrait of Los Angeles County-measure of America: a program of the social science research council. Measure of America; 2017. http://www.measureofamerica.org/ los-angeles-county/. Accessed 10 Sep 2018

26. PEW Research Center. 5 facts about illegal immigration in the U.S. [Internet]. Pew Research Center. 2019. https://www.pewre search.org/fact-tank/2019/06/12/5-facts-about-illegal-immig ration-in-the-u-s/. Accessed 25 June 2019

27. Chavez LR. Undocumented immigrants and their use of medical services in Orange County, California. Soc Sci Med. 2012;74(6):887-93.

28. $\mathrm{Ku} \mathrm{L}$, Bruen BK. Poor immigrants use public benefits at a lower rate than poor native-born citizens. Cato Institute Economic Development Bulletin. 2013;17.

29. Ponce NA, Lucia L, Shimada T. Proposed changes to immigration rules could cost California jobs, harm public health. Los Angeles: UCLA Center for Health Policy Research; 2018. p. 9.

30. Ponce NA, Quach T, Bau I, Suh D, Shimkhada R, Yue D, Hirota S. Immigrants US values, and the golden state. Health Aff. 2018. https://doi.org/10.1377/hblog20180817.59208.

31. CDC. NHIS - about the national health interview survey. 2019. https://www.cdc.gov/nchs/nhis/about_nhis.htm. Accessed 27 Mar 2019

32. Demirtas H, Freels SA, Yucel RM. Plausibility of multivariate normality assumption when multiply imputing non-Gaussian continuous outcomes: a simulation assessment. J Stat Comput Simul. 2008;78(1):69-84.

33. Bureau UC. Hispanic poverty rate hit an all-time low in 2017. The United States Census Bureau. https://www.census.gov/libra ry/stories/2019/02/hispanic-poverty-rate-hit-an-all-time-low-in2017.html. Accessed 11 Aug 2020

34. Doran KM, Ragins KT, Iacomacci AL, Cunningham A, Jubanyik KJ, Jenq GY. The revolving hospital door: hospital readmissions among patients who are homeless. Med Care. 2013;51:767-73.

35. Fazel S, Geddes JR, Kushel M. The health of homeless people in high-income countries: descriptive epidemiology, health consequences, and clinical and policy recommendations. Lancet. 2014;384(9953):1529-40.

36. Lipman BJ. America's newest working families: cost, crowding and conditions for immigrants. Washington DC: Center for Housing Policy; 2003

37. Capps R, Ku L, Fix M, Furgiuele C, Passel J, Ramchand R, et al. How are immigrants faring after welfare reform? Preliminary evidence from Los Angeles and New York City. Final Report. 2002.
38. Porteny T, Ponce N, Sommers BD. Immigrants and the affordable care act: changes in coverage and access to care by documentation status. J Immigr Minor Health. 2020. https://doi.org/10.1007/ s10903-020-01124-0.

39. Coley RL, Kull M, Leventhal T, Lynch AD. Profiles of housing and neighborhood contexts among low-income families: links with children's well-being. Cityscape. 2014;16(1):37-60.

40. Hernández D. Affording housing at the expense of health: exploring the housing and neighborhood strategies of poor families. J Fam Issues. 2016;37(7):921-46.

41. Burgard SA, Seefeldt KS, Zelner S. Housing instability and health: findings from the Michigan recession and recovery study. Soc Sci Med. 2012;75(12):2215-24.

42. Meltzer R, Schwartz A. Housing affordability and health: evidence from New York City. Hous Policy Debate. 2016;26(1):80-104.

43. Berchick ER, Hood E, Barnett JC. Health insurance coverage in the United States: 2018. Washington DC: US Department of Commerce; 2019.

44. Xu KT. Usual source of care in preventive service use: a regular doctor versus a regular site. Health Serv Res. 2002;37(6):1509-29.

45. Chinchilla M, Gabrielian S. Stemming the rise of Latinx homelessness: lessons from Los Angeles County. J Soc Distress Homeless. 2019;29:71-5.

46. Argys LM, Friedson AI, Pitts MM, Tello-Trillo DS. Losing public health insurance: TennCare reform and personal financial distress. J Public Econ. 2020;187:104202.

47. Zewde N, Eliason E, Allen H, Gross T. The effects of the ACA medicaid expansion on nationwide home evictions and evictioncourt initiations: United States, 2000-2016. Am J Public Health. 2019;109(10):1379-83.

48. Basolo V, Nguyen MT. Immigrants' housing search and neighborhood conditions: a comparative analysis of housing choice voucher holders. Cityscape. 2009;11:99-126.

49. Oliveri RC. Between a rock and a hard place: Landlords, Latinos, anti-illegal immigrant ordinances, and housing discrimination. Vand Rev. 2009;62:53.

50. Public charge fact sheet. USCIS. https://www.uscis.gov/news/ public-charge-fact-sheet. Accessed 14 Dec 2020.

51. Pollack CE, Griffin BA, Lynch J. Housing affordability and health among homeowners and renters. Am J Prev Med. 2010;39(5):15-21.

52. Luft HS. The impact of poor health on earnings. Rev Econ Stat. 1975;57(1):43-57.

53. Pelkowski JM, Berger MC. The impact of health on employment, wages, and hours worked over the life cycle. Q Rev Econ Finance. 2004;44(1):102-21.

54. Census. 2018 ACS demographic and housing estimates: 5 year estimates data profiles. https://data.census.gov/cedsci/table?d= ACS\%205-Year\%20Estimates\%20Data\%20Profiles \& table $=$ DP05\&tid=ACSDP5Y2018.DP05\&g $=0400000 U S 12,13,20,01,28$ ,29,37,40,31,45,47,48,55,56,46,16,22,23,30,49,51\&hidePreview $=$ true. Accessed 27 July 2020

Publisher's Note Springer Nature remains neutral with regard to jurisdictional claims in published maps and institutional affiliations. 